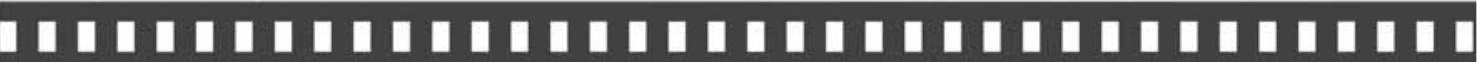 A Universidade Fotografada: Olhares e Vozes dos Estudantes de Administração

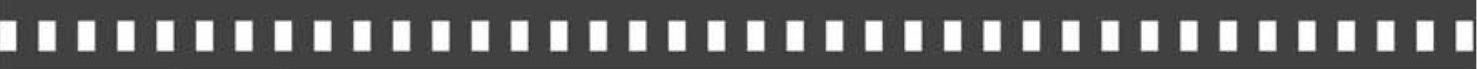

Cintia Rodrigues de Oliveira Medeiros

Artigo recebido em: 04/03/2014

Artigo aprovado em: 19/11/2014 


\title{
A Universidade Fotografada: Olhares e Vozes dos Estudantes de Administração *
}

\author{
The pictured University: \\ visions and voices of Administration students
}

Cintia Rodrigues de Oliveira Medeiros **

\begin{abstract}
Resumo: Neste artigo, a fotografia é utilizada com o objetivo de explorar as imagens de estudantes que expressam suas representações da Universidade da qual são membros. Foi solicitado aos estudantes que produzissem uma fotografia que pudesse responder à questão: "Como eu vejo esta universidade?" $e$, em seguida, escrevessem uma palavra ou expressão que a ela fosse associada. O material produzido foi analisado sob a técnica de análise de conteúdo e os resultados apontam para o caráter multifacetado, ambíguo e complexo da Universidade.
\end{abstract}

Palavras-chave: metáforas, cultura, representações sociais, imagens.

\begin{abstract}
In this paper, the photography is used in order to explore the images of students expressing their representations of the University of which they are members. Students were asked to produce a photograph that could answer the question: "How do I see this university?" and then they write a word or expression that it was associated. The material produced was analyzed from the technique of content analysis and the results point to the multifaceted, ambiguous and complex character of the University.
\end{abstract}

Keywords: metaphors, culture, social representations, images.

* Esta pesquisa foi financiada pela Fapemig.

** Doutora em Administração de Empresas pela Fundação Getúlio Vargas-SP. Coordenadora do Curso de Administração da Universidade Federal de Uberlândia. 


\section{Introdução}

As representações sociais sobre a realidade são (re)construídas pelos sujeitos que interpretam o cotidiano, construindo $\mathrm{e}$ reconstruindo sem cessar o conhecimento do "senso comum", forma pela qual as pessoas apreendem os acontecimentos e informações que vão orientar sua conduta e comunicação. Sendo um conhecimento prático que se manifesta em imagens, conceitos e símbolos, as representações sociais orientam a compreensão do contexto social, material e ideativo em que vivemos.

Morgan (1996) explica as organizações como construções sociais. Segundo esse autor, quando essas são vistas como representações, algumas questões emergem: quais são os esquemas interpretativos comuns que tornam uma organização possível? De onde eles vêm? E como esses esquemas são criados, divulgados e sustentados? Nesse sentido, as imagens que os membros fazem da organização podem dizer muito para a sua compreensão como fenômeno cultural.

Neste trabalho, o objetivo é explorar as imagens discursivas de estudantes que expressam suas representações da universidade da qual são membros. A análise é subsidiada pelo estudo de Morgan (1996) sobre as metáforas organizacionais. Para tanto, considerou-se a utilização da fotografia como recurso para coleta de material empírico. As fotos produzidas pelos participantes foram submetidas à análise de conteúdo de fotografias, em que privilegiou-se o conteúdo manifesto e latente, conforme Triviños (1987) e Ball e Smith (1992).

Inicialmente, discutem-se os conceitos e abordagens de representações sociais, bem como apresenta-se uma síntese de algumas imagens organizacionais utilizadas para compreender as organizações. Em seguida, descrevem-se os procedimentos metodológicos adotados e apresentam-se os resultados da análise. 
Ao final, as considerações encerram o artigo.

\section{Representações sociais e imagens das organizações}

O campo das representações sociais desperta interesse a todas as ciências humanas (GASKEL; BAUER, 1999; JODELET, 2001), pois esse se refere às interações sociais. É importante reconhecer, porém, que existe um extenso debate acerca do conceito de representações sociais (HARRE, 1984; FARR, 1987; DUVEEN, 1998; GASKELL; BAUER, 1999). As representações sociais são definidas por Jodelet (2001, p.8) como "uma forma de conhecimento socialmente elaborada e compartilhada, que tem um objetivo prático e concorre para a construção de uma realidade comum a um conjunto social". É nesse sentido que a autora afirma que as representações sociais orientam o comportamento humano na identificação e solução dos problemas que se apresentam, constituindo-se, então, em uma forma de expressão da realidade (FARR, 1993).

Para Moscovici (1978, p.28), a representação social é um “corpus organizado de conhecimento e uma das atividades psíquicas pelas quais os homens tornam inteligíveis a realidade física e social, inserem-se num grupo ou numa ligação cotidiana de trocas, e liberam os poderes de sua imaginação”. Gaskell e Bauer (1999, p. 167) entendem que uma representação pode ser caracterizada como a relação entre três elementos: "sujeitos ou portadores da representação; um objeto que é representado, uma entidade concreta ou uma ideia abstrata; e um projeto, ou contexto pragmático, de um grupo social dentro do qual uma representação faz sentido".

O conhecimento construído define significados, dita comportamentos e, por conseguinte, influencia o julgamento do sujeito a respeito de situações com as quais esse se depara. Não se 
trata de uma opinião do sujeito, alerta Moscovici (1978), pois essa pode ser um posicionamento acerca de uma controvérsia. Já as representações sociais se apresentam, para o autor, "como uma 'rede' de idéias, metáforas e imagens, mais ou menos interligadas livremente e, por isso, mais móveis e fluídas que teorias" (MOSCOVICI, 1978, p. 210). Nesse sentido, Spink (1993, p. 303) lembra que a representação é uma construção do sujeito social, o qual não é "apenas produto de determinações sociais nem produtor independente, pois as representações são sempre construções contextualizadas, resultados das condições em que surgem e circulam".

Uma definição operacional de uma representação social é proposta por Gaskell e Bauer (1999, p. 181): "a comparação de um sistema de comunicações em quatro formas: as estruturas de conteúdo, o processo tipificado de cultivação, as funções sócio-psicológicas, e a segmentação de meios sociais". Isso porque, conforme os autores, dependendo do contexto, identidades, atitudes, atribuições causais e ideologias podem ser reconhecidas como funções diferentes de uma estrutura específica de representação.

Os sujeitos têm maneiras específicas de compreender e se comunicar, elaborando conceitos próprios para a familiarização de algo. Assim, a realidade é percebida por uma multiplicidade de significados, de acordo com o meio social em que são apreendidas e analisadas. A sociedade é constituída de uma população miscigenada, em que são encontradas várias culturas diferentes, e o que é relativamente social para algumas, pode não ser para outras, considerando os costumes, alimentação, vestuário, crenças, educação, renda, etnias, ideologias, geradas através de convívio familiar (GASKEL; BAUER, 1999).

Howarth (2006) questiona se o propósito de pesquisas dentro da perspectiva das representações sociais é suportar ou criticar a ordem social e, ainda, se é consolidar ou transformar a ordem social. Focando nas fundações teóricas de Moscovici acerca das 
representações sociais, Howarth (2006) entende que essas são mais que ferramentas psicológicas que orientam nosso entendimento sobre os mundos que vivemos, pois, ao sustentar uma versão particular da ordem social, as representações sociais protegem interesses particulares. Assim como representações hegemônicas permeiam a construção social dominante da realidade, representações opostas podem contestar essas versões.

As representações sociais podem ser expressas por metáforas. Para Hausman (1989), a metáfora é um ícone que representa um paralelismo entre duas coisas, e ao mesmo tempo cria e refere a si mesma para que possa significar algo. As metáforas não apenas revelam similaridades, mas também podem criá-las, oferecendo insights cognitivos únicos, com condições que vão além da linguagem verbal (HAUSMAN, 1989).

Lakoff e Johnson (1980) conceberam a metáfora a partir de duas vertentes principais: a metáfora linguística, que se materializa verbalmente pelo falante de uma língua, e a metáfora conceitual, a qual é estruturada no pensamento humano. Segundo os autores, a metáfora é um mecanismo fundamental da mente, um princípio cognitivo que nos possibilita entender as experiências mais abstratas através de experiências físicas e sociais. Assim, na perspectiva da metáfora conceitual, essa não consiste em um fenômeno linguístico periférico, e sim, em uma questão cognitiva central.

Partindo dessa perspectiva, Lakoff e Johnson (1980) classificaram as metáforas, na Teoria Cognitiva, inicialmente, em três tipos: estruturais, orientacionais e ontológicas. Além dessas três, Lakoff (1993), posteriormente, apresenta as metáforas imagéticas ou metáforas do tipo one-shot. Essas metáforas se diferem das metáforas anteriores porque se utilizam apenas de imagens convencionais, ao contrário daquelas, que se utilizavam do sistema conceitual através de mapeamentos que atravessavam os domínios conceituais. Para Lakoff (1993), as metáforas do tipo "one-shot" apoiam-se em imagens concretas para dar sentido a imagens também 
concretas.

$\mathrm{Na}$ visão das organizações como culturas (SMIRCICH, 1983), é possível vislumbrar as interfaces entre cultura e metáfora. Conforme Lackoff e Johnson (1999), as metáforas representam nossa capacidade de comparar, além de conceitos, nossas experiências. Essas, por sua vez, se concretizam em frames ou modelos construídos culturalmente, isto é, de acordo com as relações intersubjetivas da sociedade. Se as metáforas são resultado de nosso modo de agir, elas encontram-se com os limites da cultura, o que implica em interfaces.

Do mesmo modo, as culturas organizacionais, entendidas como realidades construídas socialmente, são frutos de relações intersubjetivas que se desenvolvem no ambiente organizacional. Dessa forma, a análise das organizações a partir de metáforas implica na análise de construções de realidade, ou seja, em culturas organizacionais. A respeito do uso das metáforas no âmbito dos estudos organizacionais, existe crescente literatura demonstrando o seu impacto e influência formativa na linguagem, nos sistemas de conhecimento científico e no modo corriqueiro pelo qual se pensa, se vê, se fala e se expressa (TARBES, 2007; JERMIER; FORBES, 2011). Usar uma metáfora implica na oportunidade de alargar e aprofundar o pensamento, de modo que as pessoas possam entender o mundo em geral e ver as coisas de maneiras novas e agir de maneiras novas (MORGAN, 1996). Sackmann (1989, p. 465) observa que metáforas podem "sugerir uma analogia funcional entre duas situações, tornar uma ideia abstrata em algo concreto, enfatizar uma faceta particular da situação, dar significado para uma ideia nova e não familiar e torna-la mais tangível".

Para Meadows (1967), o próprio termo organização é uma metáfora, referindo-se à experiência do desordenamento e da coordenação coletiva. Morgan (1996) também afirma que todas as teorias de organização e de administração são baseadas nas imagens ou metáforas implícitas que nos induzem a ver, entender e imaginar 
situações de maneira parcial. Diversos teóricos utilizaram metáforas para entender as organizações, como, por exemplo, Burns e Stalker (1961), que abordaram a organização como um complexo organismo. Já Goffman (1959) compara as organizações com teatros e elementos da dramaturgia - atores, dramas e scripts. Segundo Crozier (1964), as organizações são arenas políticas orientadas na busca e demonstração de poder. Handy (1994), Mintzberg (1989) e Morgan (1996) também explicam as organizações utilizando-se de comparações e elementos da metáfora. Adicionando a esses trabalhos, Mutch (2006) discute e analisa a metáfora militar no campo da teoria das organizações.

O trabalho de Morgan (1996), o qual será utilizado para desenvolver a análise do material empírico do presente trabalho, é bastante reconhecido no campo dos estudos organizacionais (JERMIER; FORBES, 2011). As teorias e as explicações da vida organizacional são baseadas em metáforas que levam as pessoas a verem e a compreenderem as organizações de formas específicas, embora incompletas. Por vezes consideradas como sistemas imperfeitos e perigosos de comunicação, as metáforas foram reabilitadas por Morgan (1996) como formas fundamentais de manifestação de processos cognitivos e Sackmann (1989) coloca que as metáforas podem ser uma ferramenta útil para uma mudança organizacional ser bem sucedida.

Morgan (1996) apresenta uma visão bastante ampla da organização, procurando categorizar visões sobre a organização através de uma extensa revisão bibliográfica sobre teoria organizacional. Segundo o autor, organizações são vidas complexas e repletas de paradoxos. Dentro delas encontram-se diferentes elementos, como máquinas, pessoas, capital, tecnologia, entre outros, que fazem com elas cresçam e prosperem ou simplesmente entram em decadência. Para solucionar esse dilema, Morgan (1996) propõe uma metodologia de análise das organizações a partir do uso de diferentes metáforas, o que lhe permite ressaltar diferentes 
aspectos da organização, oferecendo uma compreensão mais eficaz da mesma.

O autor evidencia algumas metáforas (Quadro 01) que uma organização possa vivenciar, ressaltando que essas são apenas algumas delas.

Quadro 1: Síntese das Oito Metáforas de Morgan

\begin{tabular}{|l|l|l|}
\hline Metáfora & Palavras-Chave & Ideias Centrais \\
\hline Máquina & $\begin{array}{l}\text { Eficiência e } \\
\text { Racionalidade }\end{array}$ & $\begin{array}{l}\text { Organização é uma } \\
\text { burocracia, sistema } \\
\text { racional. Abordagem } \\
\text { mecanicista. }\end{array}$ \\
\hline Organismo & $\begin{array}{l}\text { Adaptação e } \\
\text { Sobrevivência }\end{array}$ & $\begin{array}{l}\text { A organização vive, } \\
\text { desenvolve, morre, sendo } \\
\text { um conjunto de partes } \\
\text { interdependentes. } \\
\text { Abordagem sistêmica. }\end{array}$ \\
\hline Cérebros & $\begin{array}{l}\text { Aprendizagem e } \\
\text { Feedback }\end{array}$ & $\begin{array}{l}\text { A organização é } \\
\text { vislumbrada como um } \\
\text { sistema de processamento } \\
\text { de informações capaz de } \\
\text { aprender a aprender. }\end{array}$ \\
\hline Cultura & $\begin{array}{l}\text { Sociedade e } \\
\text { Valores }\end{array}$ & $\begin{array}{l}\text { As organizações } \\
\text { desenvolvem uma cultura } \\
\text { própria, uma identidade } \\
\text { específica que revela o } \\
\text { modo de ser, pensar e agir } \\
\text { diante da realidade. }\end{array}$ \\
\hline
\end{tabular}




\begin{tabular}{|l|l|l|}
\hline $\begin{array}{l}\text { Sistemas } \\
\text { Políticos }\end{array}$ & $\begin{array}{l}\text { Interesse e } \\
\text { Conflito }\end{array}$ & $\begin{array}{l}\text { A organização é descrita } \\
\text { como redes de pessoas } \\
\text { interdependentes com } \\
\text { diferentes interesses, } \\
\text { conflitos, negociação e } \\
\text { poder. }\end{array}$ \\
\hline $\begin{array}{l}\text { Prisões } \\
\text { Psíquicas }\end{array}$ & $\begin{array}{l}\text { Inconsciência e } \\
\text { Repressão }\end{array}$ & $\begin{array}{l}\text { As organizações são } \\
\text { fenômenos psíquicos, } \\
\text { produto de processos } \\
\text { conscientes e } \\
\text { inconscientes, no qual as } \\
\text { pessoas se tornam reféns } \\
\text { de seus próprios } \\
\text { pensamentos. }\end{array}$ \\
\hline $\begin{array}{l}\text { Fluxo e } \\
\text { Transformação }\end{array}$ & $\begin{array}{l}\text { Movimento e } \\
\text { Complexidade }\end{array}$ & $\begin{array}{l}\text { A organização é como } \\
\text { um mecanismo de } \\
\text { mudança, evolução e } \\
\text { transformação. }\end{array}$ \\
\hline $\begin{array}{l}\text { Poder e } \\
\text { Exploração }\end{array}$ & $\begin{array}{l}\text { As organizações } \\
\text { exploram seus } \\
\text { empregados e seus } \\
\text { ambientes (comunidades) } \\
\text { para atingir seus próprios } \\
\text { objetivos. }\end{array}$ \\
\hline
\end{tabular}

Fonte: adaptado de Morgan (1996)

Ao distinguir as oito metáforas (Quadro 01), Morgan (1996) propôs uma avaliação crítica das organizações, apoiando-se na premissa de que as teorias e explicações da vida organizacional são 
baseadas em metáforas capazes de compreender as organizações de forma específica, embora incompleta, visto que as mesmas podem ser muitas coisas e nenhuma ao mesmo tempo: são complexas, ambíguas e paradoxais. É possível utilizar, em uma mesma organização, muitas imagens e metáforas para compreendê-la e modificá-la. Qualquer modelo institucional, quando é desenhado para uma organização, sofre influência de, pelo menos, algumas dessas metáforas.

Em uma análise recente das "Imagens da Organização" de Morgan (1996), Jermier e Forbes (2011) ressaltam a importância de criar novas metáforas para entender as organizações, o que seria benéfico ao campo dos estudos organizacionais. Isso porque a metáfora permite "explorar o significado de outras alegorias, tais como anomalias, paradoxos e ironias" (JERMIER; FORBES, 2011, p. 450). Mesmo considerando os benefícios da utilização das metáforas para a análise organizacional, Steger (2007) alerta que não se pode negligenciar os custos dessa análise, os quais centram-se, principalmente, na natureza do processo interpretativo. No campo da utilização das metáforas para ensinar, Tarbes (2007) e Cirka e Corrigall (2010) descrevem suas experiências para ensinar teoria das organizações e gerenciamento de crises, o que resultou na criação de novas metáforas pelos estudantes.

\section{A Pesquisa: descrição dos procedimentos}

Esta pesquisa é de natureza qualitativa (FLICK, 2009) e consiste em uma análise de imagens produzidas pelos participantes, inserindo-se no campo dos estudos culturais visuais (JAY, 2002). A utilização de dados visuais na pesquisa qualitativa é defendida por vários autores, dentre eles, Banks (2009, p.47), que considera que o filme e a fotografia "não apenas enriquecem tais estudos como 
podem dar uma visão que vai além daquela que é possível apenas com meras palavras". Nessa mesma direção, Rezende, Franco e Marquez (2013, p. 135), observam que "ampliar e aprofundar nossa leitura da imagem fotográfica implica maneiras diferentes de compreender e expressar tempo e espaço, expressando valores universais e atemporais" e, ainda, "como 'obra aberta' pode contribuir para que nos coloquemos mais efetivamente neste nosso século, qualquer que seja o espaço que ocupemos".

O campo de estudo é uma das trinta unidades acadêmicas de uma Universidade Federal localizada no interior do estado de Minas Gerais, a qual se compõe de dois cursos de graduação, de Administração e Gestão da Informação, e um curso de mestrado em Administração. Os participantes da pesquisa são estudantes do curso de Administração. Para a coleta de material empírico, utilizou-se o registro fotográfico como técnica, levando em conta a riqueza das informações obtidas. A essa técnica, associaram-se palavras e expressões utilizadas pelos participantes para atribuírem uma referência à foto por eles produzida. $\mathrm{O}$ propósito da utilização desta técnica é captar imagens subjetivas dos participantes em relação à universidade, entendendo que essas consistem nas suas representações. Essa fase do estudo foi realizada no segundo semestre letivo de 2012, tendo resultado em 126 fotos produzidas. Aos participantes, explicaram-se os objetivos do estudo e solicitou-se que produzissem uma única fotografia, no âmbito da universidade, que pudesse responder à questão: "Como eu vejo esta universidade?" Em seguida, os participantes deveriam descrever uma palavra ou expressão que refletisse a imagem. Recomendou-se aos participantes que, a seu critério, tirassem a foto do que desejassem e que estivesse relacionada ao que eles percebiam e sentiam sobre a universidade, orientando-os sobre o cuidado de não tirar fotografias que identificassem as pessoas. Contando com a possibilidade de haver imagens de pessoas nas fotos produzidas durante a pesquisa, a sua identidade foi preservada com o auxílio de 
tecnologia digital.

Quanto aos procedimentos para a análise de imagens, adotou-se a análise de conteúdo de fotografias, inspirada na análise de conteúdo segundo Triviños (1987), para quem essa técnica consiste em três fases: (1) pré-análise; (2) descrição analítica; e (3) interpretação inferencial, que compreende a interpretação do conteúdo manifesto e o conteúdo latente. Inicialmente, projetaram-se as fotos no monitor para verificar aspectos comuns e diferenciados nas fotos. Em seguida, classificou-se as fotos de acordo com as palavras e expressões descritas pelos autores das fotos. E, por fim, para a interpretação inferencial, analisou-se o conteúdo manifesto (aparência de alguma coisa na superfície ou significado pretendido) e latente (significado subjacente) da imagem, conforme Ball e Smith (1992). Cabe destacar que esse processo de análise foi subsidiado pelas metáforas organizacionais de Morgan (1996).

Ressalta-se que, neste estudo, a fotografia é utilizada no âmbito da pesquisa de campo e a decisão sobre o que fotografar é tomada pelo sujeito da pesquisa, neste caso, estudantes do curso de Administração. Vergara (2006, p.175) argumenta que "delegar ao sujeito a tarefa de selecionar imagens permite inferir acerca das percepções de cada um dos sujeitos". As palavras e fotos possibilitam a nossa interpretação sobre o "modo de ver" dos participantes, o que é sugerido por Deliberador, Alves e Lopes (2013, p. 33) quando observam, em uma experiência com estudantes, que esses utilizaram "a fotografia como linguagem expressiva acerca de sua realidade". 


\section{Imagens da Universidade: estudantes e suas diversas lentes}

A análise de conteúdo manifesto restringe-se ao que é dito, sem buscar os significados que possam estar ocultos. Já a análise do conteúdo latente orienta-se para captar sentidos implícitos. A interpretação da fotografia foi realizada pela análise de conteúdo da informação manifesta para então dirigir-se à intenção que o autor da foto disse expressar, por meio das palavras ou expressões, chegando, às vezes, a captar algo de que nem o autor tinha consciência plena. A seguir, no Quadro 2, apresenta-se a síntese da análise de conteúdo manifesto das fotos e das palavras e expressões mais recorrentes, as quais foram agrupadas conforme os aspectos similares $\mathrm{e}$ diferenciadores e, em seguida, analisados conforme as imagens da organização propostas por Morgan (1996), que é a análise do conteúdo latente.

Quadro 2: Síntese da análise da relação

entre as fotos e as oito metáforas

\begin{tabular}{|l|l|l|l|}
\hline Metáfora & Ideia central & $\begin{array}{c}\text { Conteúdo } \\
\text { manifesto das } \\
\text { imagens mais } \\
\text { recorrentes }\end{array}$ & $\begin{array}{c}\text { Conteúdo } \\
\text { manifesto } \\
\text { das palavras }\end{array}$ \\
\hline Máquina & $\begin{array}{l}\text { Eficiência e } \\
\text { Racionalidade }\end{array}$ & $\begin{array}{l}\text { Estrutura física, } \\
\text { placas } \\
\text { estragadas, } \\
\text { placa de } \\
\text { controle } \\
\text { patrimonial }\end{array}$ & $\begin{array}{l}\text { Equipamentos, } \\
\text { estrutura, } \\
\text { física, } \\
\text { desorganização, } \\
\text { controle }\end{array}$ \\
\hline
\end{tabular}




\begin{tabular}{|c|c|c|c|}
\hline Organismo & $\begin{array}{l}\text { Satisfação de } \\
\text { necessidades }\end{array}$ & $\begin{array}{l}\text { Placa de } \\
\text { formatura, } \\
\text { Restaurante } \\
\text { universitário }\end{array}$ & $\begin{array}{l}\text { Bem-estar, } \\
\text { realizações, } \\
\text { reconhecimento, } \\
\text { status }\end{array}$ \\
\hline Cérebro & $\begin{array}{l}\text { Aprendizagem } \\
\text { coletiva }\end{array}$ & $\begin{array}{l}\text { Biblioteca, } \\
\text { laboratórios, } \\
\text { salas de aula }\end{array}$ & $\begin{array}{l}\text { Conhecimento, } \\
\text { aprendizado, } \\
\text { palestras e } \\
\text { debates, }\end{array}$ \\
\hline Cultura & $\begin{array}{l}\text { Sociedades, } \\
\text { grupos e } \\
\text { Valores }\end{array}$ & $\begin{array}{l}\text { Centro de } \\
\text { convivência, } \\
\text { grupos de } \\
\text { pessoas, cartaz } \\
\text { institucional }\end{array}$ & $\begin{array}{l}\text { Cultura, espaço } \\
\text { para encontrar } \\
\text { com Deus, } \\
\text { interação, } \\
\text { diversidade, } \\
\text { inclusão }\end{array}$ \\
\hline $\begin{array}{l}\text { Sistemas } \\
\text { Políticos }\end{array}$ & $\begin{array}{l}\text { Negociação de } \\
\text { interesses }\end{array}$ & $\begin{array}{l}\text { Reitoria, } \\
\text { cartazes de } \\
\text { movimento } \\
\text { estudantil }\end{array}$ & $\begin{array}{l}\text { Discussão para } \\
\text { melhorias, } \\
\text { instituição } \\
\text { pública, } \\
\text { confronto de } \\
\text { ideias }\end{array}$ \\
\hline Prisão Psíquica & $\begin{array}{l}\text { Inconsciente } \\
\text { coletivo }\end{array}$ & $\begin{array}{l}\text { Cartazes, ruas } \\
\text { do campus, } \\
\text { escadaria do } \\
\text { campus }\end{array}$ & $\begin{array}{l}\text { Meu futuro, } \\
\text { trajetória da } \\
\text { minha vida, } \\
\text { construção de } \\
\text { sonhos, } \\
\text { caminho para o } \\
\text { sucesso }\end{array}$ \\
\hline
\end{tabular}




\begin{tabular}{|l|l|l|l|}
\hline $\begin{array}{l}\text { Fluxo e } \\
\text { Transformação }\end{array}$ & $\begin{array}{l}\text { Mudança } \\
\text { orgânica }\end{array}$ & $\begin{array}{l}\text { Prédios em } \\
\text { construção e } \\
\text { reforma }\end{array}$ & $\begin{array}{l}\text { Possibilidades } \\
\text { de mudança, } \\
\text { crescimento } \\
\text { pessoal, }\end{array}$ \\
\hline $\begin{array}{l}\text { Instrumento de } \\
\text { Dominação }\end{array}$ & $\begin{array}{l}\text { Exploração } \\
\text { Dominação }\end{array}$ & $\begin{array}{l}\text { Carros de luxo, } \\
\text { estacionamento } \\
\text { lotado, }\end{array}$ & $\begin{array}{l}\text { Desigualdade } \\
\text { social }\end{array}$ \\
\hline
\end{tabular}

Fonte: Elaborado a partir de Morgan (1996) e dados de pesquisa

Universidade como máquina. $O$ conjunto de imagens que refletem as organizações como máquina e cujas palavras expressam que os autores veem a universidade como "equipamentos" e "estrutura física" está associado ao papel desempenhado pelas partes no funcionamento do todo. Morgan (1996) descreve essa metáfora com sustentação na Teoria Clássica da Administração e na Administração Científica. Nessa metáfora, entende-se que a organização opera de uma maneira rotineira, eficiente, confiável e previsível. De acordo com Morgan (1996), essa é a teoria que tem orientado, predominantemente, a organização e a administração desde a Revolução Industrial. Ela trouxe enormes benefícios, aumentando em milhares de vezes a capacidade de produção, mas, ao mesmo tempo, gerou inúmeras deficiências, como a rigidez, que impede as organizações de se adaptarem e fluírem com as mudanças. No caso da universidade, a estrutura burocrática criada para alcançar a eficiência propicia disfunções que acarretam em problemas na estrutura física e social (Figura 1). 
Figura 1: Fotografia do Bloco 3Q

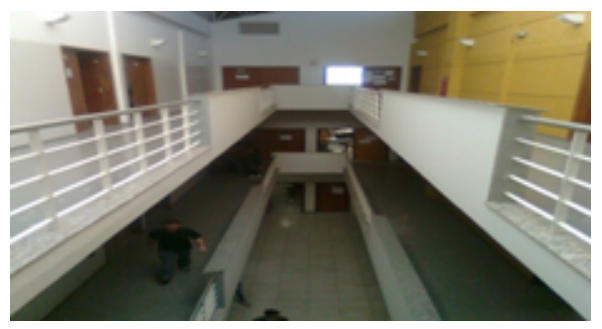

Fonte: material empírico produzido pelos estudantes

Universidade como organismo. Nessa metáfora, Morgan (1996) associa o conceito de sistemas abertos da biologia à imagem de um organismo procurando adaptar-se e sobreviver em um ambiente em mudança. Segundo Morgan (1996), a metáfora auxilia na compreensão das organizações como conglomerados de seres humanos, negócios e necessidades técnicas inter-relacionados, encorajando a aprender a arte da sobrevivência corporativa e da adaptação às mudanças. Nesse sentido, as imagens e expressões associadas com a satisfação das necessidades dos participantes representam essa metáfora, como o Restaurante Universitário, o indoor de boas vindas que valoriza os estudantes (Figura 2).

Figura 2: Foto do indoor de boas vindas à Universidade

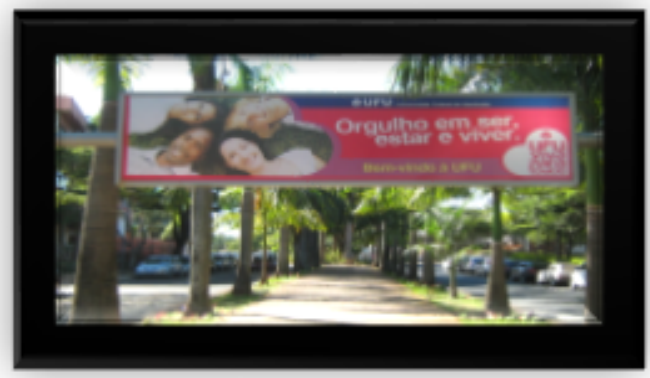

Fonte: material empírico produzido pelos estudantes 
Universidade como cérebro. Para desenvolver essa metáfora, Morgan (1996) parte da premissa que a organização, de modo similar ao cérebro, é um sistema de processamento de informações capaz de aprender a aprender. As imagens e expressões relacionadas com a busca e geração de conhecimento representam essa metáfora. A biblioteca da universidade (Figura 3) é uma das fotos mais recorrentes, junto com as palavras conhecimento e aprendizagem. Conforme abordado por Morgan (1996), à medida que foi desenvolvido uma economia baseada no conhecimento, em que a informação e o aprendizado são recursos-chaves, a inspiração de um cérebro vivo capaz de aprender oferece uma imagem poderosa para a criação de organizações ideais, perfeitamente adaptadas aos requisitos da era digital.

Figura 3: Foto da biblioteca central da Universidade

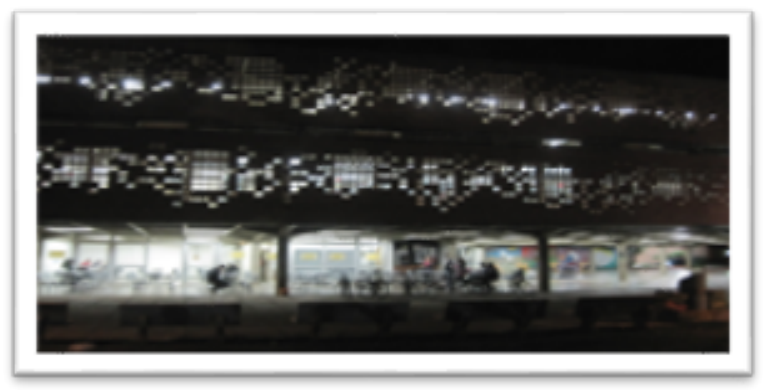

Fonte: material empírico produzido pelos estudantes

Universidade como culturas. Quando as organizações são consideradas como culturas, elas são vistas como minissociedades, com seus valores, rituais, ideologias e crenças próprias que sustentam a organização como uma realidade construída socialmente, isto é, um conjunto de padrões com significado comum (MORGAN, 1996). A metáfora da cultura foca a atenção no lado humano da organização, ressaltando o significado simbólico de cada 
aspecto virtual da vida organizacional. Fotos do centro de convivência do campus e da saguão da lanchonete, onde grupos de estudantes se reúnem para as interações fora da sala de aula estão entre as mais recorrentes (Figura 4), com as expressões "sociabilidade", "convívio social", entre outras.

Figura 4: Foto do saguão do bloco onde fica a lanchonete

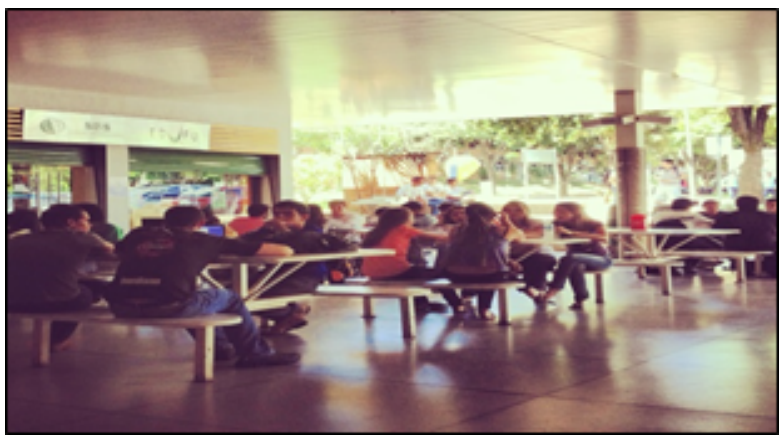

Fonte: material empírico produzido pelos estudantes

Morgan (1996) explica que essa metáfora ajuda a repensar quase todos os aspectos do funcionamento corporativo, inclusive a estratégia, a estrutura e a natureza da liderança e da administração. $\mathrm{O}$ ponto central consiste em que as organizações desenvolvem uma cultura muito própria, uma identidade específica que revela o modo de ser, pensar e agir diante da realidade.

Conforme Morgan (1996), as crenças e as ideias que as organizações possuem de si mesmas, bem como daquilo que pensam fazer com respeito a seu ambiente, influenciam, sobremaneira, na materialização de seus objetivos, encorajando-as, também, para a formulação e o estabelecimento da sua estratégia empresarial. Um participante produziu a foto de uma faixa no campus convidando para a "Missa no campus", referindo-se à instituição como um 
espaço para encontrar-se com Deus. A palavra diversidade foi referida por vários sujeitos. As imagens relacionadas a essa palavra contemplam grupos de pessoas conversando, a acessibilidade do campus para pessoas com deficiência e, até mesmo um expositor de doces de diferentes cores e formatos foi utilizado para expressar a diversidade.

Universidade como sistema político. Como propõe Morgan (1996), a metáfora política encoraja olhar as organizações como redes de pessoas interdependentes com diferentes interesses, conflitos, habilidades de negociação e fontes de poder que se unem com o propósito de satisfazer as suas necessidades básicas, desenvolver uma carreira profissional ou de perseguir metas além de seu trabalho. Essa metáfora ajuda a desmistificar a visão racionalista da organização e dá luz à visão de que existe um jogo político entre os atores organizacionais, diferentemente, de outras visões que olham as organizações como empreendimentos interligados e racionais que perseguem um objetivo comum. Para Morgan (1996), ao entender as organizações em termos políticos, aceita-se o fato de que a política é um aspecto inevitável da vida corporativa. Sendo assim, dirigentes eficazes são atores políticos habilidosos que reconhecem o contínuo jogo entre interesses concorrentes e que utilizam o conflito como uma força positiva. As imagens que representam essa metáfora são o prédio da reitoria, faixas do movimento estudantil e da greve de docentes, o que lembra o espaço democrático constituído nas universidades.

Universidade como prisão psíquica. Baseada nas teorias psicanalíticas, essa perspectiva oferece uma percepção detalhada sobre as ligações entre organização, o inconsciente e o comportamento, que geralmente são ignoradas pela teoria tradicional da administração. Essa metáfora, conforme Morgan (1996), sugere que as organizações são fenômenos psíquicos, ou seja, o produto de processos conscientes e inconscientes, no qual as pessoas se tornam reféns de seus próprios pensamentos, ideias, crenças e preocupações. 
Pressupostos falsos, crenças pré-estabelecidas, regras operacionais numerosas e sem questionamentos, entre outras premissas e práticas, podem combinar-se para formar pontos de vista muito estreitos do mundo, fornecendo tanto uma base como uma limitação para ações organizadas. Esses pressupostos, ao mesmo tempo em que criam um modo de enxergar, sugerindo uma forma de agir, tendem também a gerar maneiras de não ver e de eliminar a possibilidade de ações associadas a visões alternativas da realidade.

Figura 4: Fotografia da escada de acesso ao Centro de Convivência

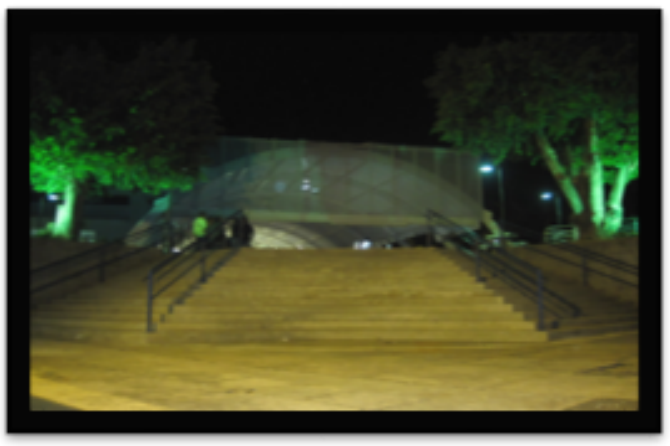

Fonte: material empírico produzido pelos estudantes

As fotos (Figura 5) e palavras associadas a essa metáfora são sucesso, sonho, futuro, indicando que estar na universidade é atender uma premissa de que esse é o caminho para o sucesso. Assim, conforme exposto por Morgan (1996), embora as organizações possam ser realidades socialmente construídas, essas assumiram existência e poder próprios que lhes permitem exercer certo grau de controle sobre seus criadores.

Universidade como fluxo e transformação. Nessa metáfora, Morgan (1996) propõe uma visão da organização segundo a qual o importante é entender a lógica da mudança, da evolução. Morgan 
(1996) destaca que aquela organização que realmente quer entender o seu ambiente, deve, primeiro, tentar se conhecer, visto que a compreensão do ambiente organizacional é sempre uma projeção dela mesma. De acordo com essa visão, muitas organizações encontram sérios problemas para lidar com o mundo exterior por não reconhecerem que esse como parte de seus ambientes. Nesse sentido, deve-se considerar que as organizações mudam e se transformam em conjunto com seu meio ambiente (fornecedores, clientes, trabalhadores, coletividade, concorrência), o que implica dizer que o padrão de organização que surge com o passar do tempo é resultado de um processo de evolução. As fotos associadas a essa metáfora são os prédios em reforma que, por sua vez, foram relacionadas com a mudança pelos autores.

Universidade como instrumento de dominação. As imagens associadas a essa metáfora foram aquelas que acompanhadas de expressões como "desigualdade social". Essas fotos foram de carros luxuosos estacionados no campus, estacionamentos lotados e carros estacionados em locais proibidos. A interpretação é de que o campus, um espaço público, acaba sendo ocupado de forma desigual, refletindo as desigualdades do país. Assim, a instituição pública é associada aos processos de dominação social. Nessa metáfora, Morgan (1996) aborda as organizações como formas de exploração, isto é, o autor centraliza no modo pelo qual as organizações exploram seus empregados, seus ambientes (comunidades), e a economia mundial para atingir seus próprios objetivos. Ao longo da história, organizações têm sido associadas a processos de dominação social nos quais indivíduos ou grupos encontram formas de impor a respectiva vontade sobre os outros.

Morgan (1996) ainda afirma que o real valor dessa perspectiva consiste no fato de essa demonstrar que, até as formas mais racionais e democráticas de organização podem resultar em modelos de dominação. Como exemplo, o autor cita que os objetivos racionais de maior rentabilidade ou de crescimento organizacional provocam, 
não poucas vezes, impactos negativos intrínsecos nas organizações, tanto nos empregados como no seu ambiente, embora esses não sejam, necessariamente, intencionais. As representações sociais dos estudantes pesquisados apontam para as oito imagens de Morgan (1996), as quais foram selecionadas para subsidiar a análise. Outras metáforas podem ser utilizadas para essa interpretação, contudo, sem qualquer reducionismo, a análise é suficiente para apontar a natureza complexa das organizações.

\section{Discussão}

Ao evidenciar as imagens dos estudantes, aponta-se para um conhecimento socialmente elaborado que concorre para a construção de uma realidade, conforme Jodelet (2001). Ainda, esse conhecimento orienta o comportamento dos estudantes nos momentos de identificar e resolver os problemas enfrentados na universidade. Pensar a universidade como um instrumento de dominação, por exemplo, pode influenciar o julgamento do sujeito, nesse caso, estudantes, a respeito das situações cotidianas, pois, conforme Moscovici (1978), não se trata de uma opinião, mas sim, da realidade construída. Nesse aspecto, considera-se o entendimento de Howarth (2006) sobre as metáforas serem mais do que ferramentas psicológicas, visto que visões opostas foram identificadas.

A despeito de o trabalho de Morgan (1996) já ter sido frequentemente utilizado na análise das organizações, principalmente, no campo dos estudos organizacionais, é preciso considerar que a compreensão do universo simbólico dos estudantes por meio das representações sociais se mostra como uma via para entender as diferentes significações que esses constroem acerca da universidade. Conforme Lakoff e Johson (1980), a metáfora, como um mecanismo fundamental da mente, possibilita aos sujeitos o 
entendimento de suas experiências mais abstratas através de experiências concretas. Nesse caso, os estudantes manifestaram em imagens concretas o seu entendimento acerca da sua vivência na universidade.

Consoante com Tarbes (2007), Cirka e Corrigall (2010) e Jermier e Forbes (2011), deixou-se a interpretação da pesquisadora encontrar outra metáfora. Diante de fotos que mostravam as performances artísticas, eventos científicos, comemorações institucionais ocorridas em diversos espaços da universidade, ao mesmo tempo, bem como os intercambistas de diversos países presentes na universidade, proponho a metáfora Polytheama. Essa palavra, de origem grega, (poly = muitos e Thema = espetáculos), ou Politeama, teve seu significado estendido para referir-se ao teatro que oferece grande variedade de espetáculos, como: peças teatrais, cinemas, musicais, circos e outras apresentações artísticas e culturais. Nesse sentido, é um espaço em que se apresenta uma diversidade de especialistas, culturas, línguas, símbolos, sons, imagens, cenas, vozes e textos. A analogia da Politeama com a universidade é feita por essa representar um espaço que retrata a interface entre metáfora e cultura.

\section{Considerações Finais}

Nesta pesquisa, exploram-se as imagens de estudantes em relação à universidade da qual são membros. Essas imagens foram produzidas por fotografias e analisadas como as representações sociais que os autores fazem da universidade e, em seguida, analisadas a partir das metáforas organizacionais propostas por Morgan (1996) para compreender as organizações. Conforme exposto, pode-se perceber que a metáfora é um mecanismo fundamental da mente, um princípio cognitivo capaz de possibilitar o entendimento das experiências mais abstratas, podendo ser 
conduzida para diversas áreas do conhecimento, inclusive no campo da Administração em geral e, particularmente, das organizações.

Esta pesquisa tem implicações práticas e teóricas. No que tange às implicações para a prática, o estudo apontou para a importância da metáfora no ambiente corporativo, já que a mesma é útil para a compreensão dos conflitos que surgem internamente. A metáfora é um processo cognitivo que promove a produção de esquemas imagéticos básicos, e, consequentemente, facilita o processo de análise de um problema. Sendo assim, ao aumentar a capacidade crítica e de compreensão frente aos problemas gerados pelo comportamento humano nas organizações, os gestores estarão mais aptos para administrarem os conflitos interno $\mathrm{e}$ as transformações constantes do ambiente externo.

Quanto às implicações teóricas, esta pesquisa contribui para ampliar os estudos sobre cultura organizacional e sua interface com as metáforas. A abordagem das oito metáforas organizacionais de Morgan (1996) ilustradas por meio de representações sociais pode oferecer insights sobre o modo de ver e interpretar o contexto organizacional, auxiliando na compreensão dos aspectos intrínsecos das organizações e seu caráter multifacetado, ensejando outras pesquisas. Ainda, ressalta-se que, no campo da Administração, métodos e técnicas com utilização de dados visuais para coleta e análise de dados da vida social são pouco utilizados, mesmo que ofereçam oportunidades ricas para a análise do objeto de pesquisa do campo. Ademais, a exemplo de Rezende, Franco e Marquez (2013), considera-se que os estudantes manifestaram, no registro fotográfico, seus olhares sobre a universidade e sobre o mundo.

Este estudo tem limitações, dentre as quais apontam-se: o fato de a análise ser fruto da intepretação da pesquisadora, e, ainda, a análise restringiu-se à temática, não considerando a riqueza da produção de imagens para a análise das organizações. Diante das possíveis contribuições e das limitações do estudo, sugere-se a realização de estudos que se proponham a: (1) utilizar outras 
metáforas além daquelas propostas por Morgan; (2) aprofundar nas análises de outros elementos da fotografia, como a luz, perspectiva, entre outros; (3) considerar, comparativamente, sujeitos de outras unidades acadêmicas; (4) inserir a análise do contexto social e histórico da produção das fotos; e (5) estimular a criação de novas metáforas.

\section{Referências}

\section{BALL, M.; SMITH, G.W.H. Analysing Visutal Data. London:} Sage Publications, 1992.

CAMPOS, R. Imagem e tecnologias visuais em pesquisa social: tendências e desafios. Análise Social, v. XLVI (199), p. 237-259, 2011.

CIRKA, C. C.; CORRIGALL, E. A. Expanding Possibilities Through Metaphor: Breaking Biases to Improve Crisis Management. Journal Of Management Education, v. 34, n. 2, p. $303-323,2010$.

DELIBERADOR, L. M. Y.; ALVES, F. A.; LOPES, M. F. A fotografia como linguagem para a formação cidadã. Discursos Fotográficos, v.9, n.14, p.13-35, jan./jun. 2013.

DUVEEN, G. The psychological production of ideas: social representations and psychologic. Culture and Psychology, v. 4, p. 455-472, 1998.

FARR, R. M. Common sense, science and social representation. Public Understanding of Science. v. 2, p. 189-205, 1993. 
FARR, R. M. Social Representations: A French tradition of research. Journal for the Theory of Social Behavior, v. 17, p. 343-370, 1987.

FLICK, U. Desenho da pesquisa qualitativa. Porto Alegre: Artmed, 2009.

GASKELL, G.; BAUER, M. W. Towards a paradigm for research on social representations. Journal for the Theory of Social Behavior. v. 29, n.2, p. 163-186, 1999.

GOFFMAN, E. The Presentation of Self in Everyday Life. New York: Doubleday,1959.

HARRE, R. Some reflections on the concept of "Social Representation”. Social Research, v. 51, p. 927-938, 1984.

HANDY, C. Deuses da Administração. São Paulo: Senac, 1994.

HAUSMAN, C. R.. Metaphor and Art: interactionism and reference in the verbal and nonverbal arts. Cambridge University Press, 1989.

HOWARTH, C. "A social representation is not a quiet thing". Exploring the critical potential of social representations theory. British Journal of Social Psychology, v. 45, n.11, p. 65-86, 2006.

JAY, M. Cultural relativism and the visual turn". Journal of visual culture, v. 1, n. 3, p. 267-79, 2002.

JERMIER, J. M.; FORBES, L. C. Metaphor as the Foundation of Organizational Studies: Images of Organization and Beyond. Organization \& Environment, v. 24, n. 4, p. 444 -458, 2011. 
JODELET, D. Representações sociais: um domínio em expansão. In: JODELET, D. (org). As representações sociais. Rio de Janeiro: EdUERJ, 2001.

KÖVECSES, Z. Metaphor and Culture. Acta Universitatis Sapientiae, Philologica, v. 2, n. 2, p. 197-220, 2010.

LAKOFF, G; JOHNSON, M. Metaphors we live by. Chicago: The University of Chicago Press, 1980.

LAKOFF, G. The Contemporary Theory of Metaphor. In:

ORTONY, A. (ed.) Metaphor and Thought. 2. Ed., Cambridge: Cambridge University Press, 1993.

MEADOWS, P. The metaphors of order: Toward a taxonomy of organization theory. In GROSS, L.(ed.), Sociological Theory: Inquiries and Paradigms. New York: Harper \& Row, 1967.

MINTZBERG, H. Mintzberg on Management: Inside our Strange World of Organizations. New York: The Free Press, 1989.

MORGAN, G. Imagens da Organização. São Paulo: Atlas, 1996.

MOSCOVICI, S. A Representação Social da Psicanálise. Rio de Janeiro, Jorge Zahar, 1978.

REZENDE, L. A.; FRANCO, S. A. P.; MARQUEZ, L. Fotografias e leituras de mundo: arte e educação. Discursos Fotográficos, v.9, n.15, p.113-138, jul./dez. 2013.

SACKMANN, S. The role of metaphors in organization transformation. Human Relations, v. 42, n. 6, p. 463-485, 1989. 
SMIRCICH, L. Concepts of Culture and Organizational Analysis. Administrative Science Quaterly, v. 28, n.3, p.339-358, 1983.

SPINK, M. J. P. O conceito de representações sociais em Psicologia Social. Cad. Saúde Públ., Rio de Janeiro, v. 9, n. 3, p. 300-308, jul/sep, 1993.

STEGER, T. The Stories Metaphors Tell: Metaphors as a Tool to Decipher Tacit Aspects in Narratives. Field Methods, v. 19, n.3, p. 3-23, 2007.

TARBES, T. D. Using Metaphors to Teach Organization Theory. Journal Of Management Education, v. 31, n. 4, p. 541-554, 2007.

TRIVIÑOS, A. N.S. Introdução à pesquisa em ciências sociais: a pesquisa qualitativa em educação. São Paulo: Atlas, 1987.

VERGARA, S.C. A utilização da construção de desenhos como técnica de coleta de dados. In: VIEIRA, M;M;F; ZOUAIN, D.M. Pesquisa Qualitativa em Administração. Rio de Janeiro: FGV Editora, 2006. 